\title{
A case of idiopathic edema after opioid abuse cessation: can failed aldosterone escape be implicated?
}

\author{
Ashutosh Ratnam ${ }^{1 *}$, V. K. Sashindran², Anup Kanwar ${ }^{2}$
}

${ }^{1}$ Department of Psychiatry, ${ }^{2}$ Department of Medicine, Armed Forces Medical College, Pune, Maharashtra, India

Received: 21 November 2018 Accepted: 28 December 2018

\section{*Correspondence to:}

Dr. Ashutosh Ratnam, Email: ashratnam@yahoo.com

Copyright: (C) the author(s), publisher and licensee Medip Academy. This is an openaccess article distributed under the terms of the Creative Commons Attribution NonCommercial License, which permits unrestricted noncommercial use, distribution, and reproduction in any medium, provided the original work is properly cited.

\begin{abstract}
Edema is a recognized complication of ongoing heavy opioid use, regardless of the means of delivery or the specifics of the drug in question. The mechanism responsible remains incompletely understood. Hypotheses currently offered include increased Anti-Diuretic Hormone (ADH) secretion, histamine-mediated permeability changes, independent opioid-receptor mediated fluid retention and an exacerbation of pre-existing vascular compromise. Authors report a case of a $39 \mathrm{yr}$ old lady in whom edema emerged 7 months after cessation of opioid abuse. All secondary causes of edema were excluded by an exhaustive battery of investigations. The edema failed to recede with loop diuretics, and resolved only on institution of spironolactone, on which she maintained improvement. This case study reinforces hypotheses of ADH likely mediating opioid associated edema and suggests that aldosterone receptor antagonists are probably a superior class of drugs in opioid-associated edema. It also suggests that the physiological changes caused by opioid use that are responsible for edema are likely stable and persist well beyond the period of actual use. Reformed opioid abusers who never received OST are a huge population whose unique physiological status is likely to yield valuable insights into not just the pathology of opioid-abuse related edema, but the pathology of opioid use as a whole.
\end{abstract}

Keywords: Aldosterone, Edema, Opioid analgesics, Opioid-related disorders

\section{INTRODUCTION}

A considerable quantum of data suggests that the use of opioid drugs is associated with peripheral edema regardless of the means of delivery or of the specifics of the opioid used, be it oral methadone, transdermal fentanyl or epidural morphine..$^{1-3}$ Unfortunately, the means by which opioids as a collective appear to cause edema is still poorly understood. A number of hypotheses attempting to explain the phenomenon already exist - opioids have been conjectured to induce Anti-diuretic Hormone release, to produce Histamine mediated changes in tissue permeability and to exacerbate pre-existing vascular pathology. However, most reports of opioid-associated edema describe heavy ongoing opioid use, in which context any of the above hypotheses can stand valid.
Authors present a case of edema instead emerging in a patient as a late complication after cessation of abuse. Our patient's clinical presentation, disease trajectory and almost therapeutic response to Spironolactone implicate failed aldosterone escape as a possible mechanism for opioid-abuse related edema.

\section{CASE REPORT}

A 39 year old female nursing home attendant who had been abusing the prescription opioid Pentazocine on a daily basis for the preceding year was brought to the outpatient psychiatric treatment center. She had been stealing ampoules of the injectable lactate form of the drug from the nursing home she was working in, and was 'skinpopping' it, injecting herself subcutaneously over parts of 
the body concealed by clothing (upper thighs, hips, buttocks, etc). At the time of presentation, she was using $120 \mathrm{mg}$ of sterile injectable pentazocine a day, often coadministering $25-50 \mathrm{mg}$ of the injectable anti-histamine Promethazine. She was emaciated, could only stand with support, and had developed purulent sinuses over the sites of injection. Authors could not offer her opioid substitution therapy (OST) as our center is not a licensed OST establishment, and the patient was unable to afford travel to the nearest such center. A mutual decision was reached to attempt a 'cold-turkey' detoxification, using supportive medication to palliate emergent withdrawal. The patient manifested a predictable cluster of opioid withdrawal symptoms - insomnia, abdominal cramps, muscle aches, diaphoresis and diarrhea. These were managed using tapering doses of lorazepam, tramadol, ibuprofen, tizanidine and loperamide with reasonable success. Though she did lapse initially and use drugs on 3 4 occasions, some 02 months into treatment, the patient had stopped all opioid use and was off all the above symptomatic treatment. Her abstinent status was corroborated by serial negative urine drug screens and by the accounts of family members who lived with her.

For the patient's residual complaint of sleep difficulty (she would usually abuse pentazocine at night to help with sleep) she was prescribed clonazepam, to which she showed transient response. Over the following weeks, a prominent dysphoria emerged, with symptoms meeting criteria for a moderate depressive episode. She was treated with tab. mirtazepine $30 \mathrm{mg}$, with which both her mood improved, and her sleep difficulties resolved.

Some 07 months after complete cessation of opioid use, the patient noted periorbital edema when she woke up in the morning, and a steadily worsening swelling of the feet. Within 03 weeks, she had developed bilateral pitting pedal edema extending up to the knees, florid facial puffiness, and she would become breathless on walking 100 meters. Evaluation at this time revealed BP $110 / 70 \mathrm{~mm} \mathrm{Hg}$ and tachycardia $(\mathrm{P}=120 / \mathrm{min})$ but there was no rise in jugular venous pressure (JVP). An exhaustive investigation battery was performed to ascertain the cause of the edema. Tests performed included a urine examination, a complete blood count, renal function tests, serum electrolyte levels, thyroid function tests, serum cortisol levels, a 2D Echocardiogram and treadmill test, an abdominal ultrasound, and a spirometry, all of which were normal. The only derangement that emerged was a grade II fatty liver. Her liver function profile was however normal (S. Bilirubin $=0.8 \mathrm{mg} \%$, AST/ALT-22/32 IU/L, S. albumin $=3.9 \mathrm{gm} \%$, S. globulin $2.1 \mathrm{~g} / \mathrm{dL}$ ). Color doppler flow imaging demonstrated normal arterial and venous flow in the lower limbs, and no signs of active vasculitis. Accommodating the remote possibility that the symptoms could be due to mirtazepine, the drug was stopped. This did not change the pattern or quantum of edema.

All conceivable organ-system derangement and local insult based etiologies had been aggressively probed for and excluded, and the edema was now deemed idiopathic. The patient was first prescribed tab. frusemide $40 \mathrm{mg}$ to which she showed an only temporary and partial response - the edema would reduce by half for the duration of frusemide use, and immediately return to its earlier severity when the loop diuretic was discontinued.

Author achieved far better results with institution of Tab lasilactone (frusemide $20 \mathrm{mg}+$ spironolactone $50 \mathrm{mg}$ ). Within a period of 1 week, considerable resolution took place, and the patient was effectively free of all edema by 2 weeks. She has maintained this improvement and her breathlessness has also shown an improving course with institution of a graded exercise program.

\section{DISCUSSION}

The major theories put forward to explain opioid-induced edema are:

a) Opioids induce an increase in Anti-Diuretic Hormone $(\mathrm{ADH})$ release, a concept that was first proposed by de Bodo RC, as a working hypothesis to explain the antidiuretic properties of morphine. ${ }^{4}$ Animal studies measuring ADH levels following opioid administration have yielded divergent results, with some studies demonstrating increased ADH levels while others decreased levels. ${ }^{5-8}$ However as has previously been noted, such conflicting reports are from studies measuring ADH levels up to $24 \mathrm{hrs}$ after acute administration of opioids. ${ }^{3}$ Ruan et al, observed that edema following an epidural morphine trial emerged after 04 days, and speculated that chronic opioid administration (consistent with dependence pattern use) would likely produce sustained elevations in ADH that could contribute to edema. ${ }^{3}$

b) Opioids activate central opioid receptors to produce changes in urine formation and fluid retention using a mechanism distinct from the mere increase of $\mathrm{ADH} .{ }^{9}$ This hypothesis is lent merit by the manner in which intraventricular injections of $\mathrm{ADH}$ and opioids both produced oliguria but caused diametrically opposite changes in urinary sodium and potassium concentrations $\mathrm{ADH}$ produced urine with high sodium and potassium concentrations, while opioids produced urine with low electrolyte concentrations. ${ }^{10}$ It is reasonable to assume that if opioids can produce unique changes in urine formation, quantity and composition, they can similarly affect fluid retention.

c) Opioid-induced histamine release may contribute to peripheral edema. It has been reliably demonstrated that systemic morphine induces histamine release. In fact, the vasodilatory effects of morphine have been shown to be almost entirely histamine mediated, working independently of opioid mu receptor action. ${ }^{11-13}$ Opioids directly act on mast cells to stimulate histamine release. The histamine thus produced could, by its local actions, cause changes in vessel permeability leading to edema. However, opioids differ in their ability to promote 
histamine release, e.g. while morphine and pethidine are potent histamine releasers, fentanyl and tramadol are not. ${ }^{14-}$ 16

d) Pre-existing propensities for leg edema and vascular insufficiency decompensate and manifest clinically in the face of additional opioid-induced vasodilatation. Aldrete et al, considered this as an explanation for 5 cases of leg edema in 23 patients on long-term intrathecal opioids, and thereby concluded that pre-existing venous insufficiency may be considered relative contraindications for continued use of intrathecal opoids in patients with chronic pain. ${ }^{17}$

Table 1: Focused review of previously reported cases of opioid-associated edema.

\begin{tabular}{|c|c|c|c|c|}
\hline \multicolumn{5}{|c|}{ Case reported by } \\
\hline & Gardner-Nix ${ }^{1}$ & & & Longwell et al $^{26}$ \\
\hline Age/sex & $67 / \mathrm{F}$ & $57 / \mathrm{F}$ & $72 / \mathrm{M}$ & $26 / F$ \\
\hline \multirow{4}{*}{$\begin{array}{l}\text { Opioids and } \\
\text { route }\end{array}$} & \multirow{2}{*}{$\begin{array}{l}\text { 90mg Morphine BD + 10-20mg } \\
\text { Morphine QID }\end{array}$} & $\begin{array}{l}\text { Oxycodone } \\
\text { 320mg QID }\end{array}$ & Morphine 400mg TDS & \multirow{4}{*}{$\begin{array}{l}\text { Methadone } \\
100 \mathrm{mg} / \text { day }\end{array}$} \\
\hline & & Fentanyl & \multirow{3}{*}{$\begin{array}{l}\text { Oxycodone SR } 80 \mathrm{mg} \\
\text { TDS } \rightarrow 120 \mathrm{mg} \text { TDS }\end{array}$} & \\
\hline & \multirow{2}{*}{ Fentanyl transdermal $(50 \rightarrow 100 \mu \mathrm{g} / \mathrm{hr})$} & $\begin{array}{l}\text { transdermal } \\
200 \mu \mathrm{g} / \mathrm{hr}\end{array}$ & & \\
\hline & & $\begin{array}{l}\text { Methadone } \\
30 \mathrm{mg} \rightarrow 480 \mathrm{mg}\end{array}$ & & \\
\hline \multirow{6}{*}{$\begin{array}{l}\text { Treatment } \\
\text { duration prior } \\
\text { to edema onset }\end{array}$} & $\begin{array}{l}\text { Years (motor vehicle accident, } \\
\text { developed Kyphoscoliosis, } \\
\text { Osteoporosis, Sciatica, Thoracic } \\
\text { vertebra fracture and cervical fusion) }\end{array}$ & \multirow{6}{*}{$\begin{array}{l}\text { Years (after } \\
\text { lumbo-sacral } \\
\text { spine surgery) }\end{array}$} & \multirow{6}{*}{$\begin{array}{l}\text { Years (traumatic C5 } \\
\text { fracture with two } \\
\text { anterior and one } \\
\text { posterior fusion) }\end{array}$} & \multirow{6}{*}{5 months } \\
\hline & Kyphoscoliosis & & & \\
\hline & Osteoporosis & & & \\
\hline & Sciatica & & & \\
\hline & Thoracic vertebra fracture & & & \\
\hline & Cervical fusion & & & \\
\hline $\begin{array}{l}\text { Edema } \\
\text { distribution }\end{array}$ & Ankle, Mid-calf & $\begin{array}{l}\text { Legs, thigh, } \\
\text { arms, hands }\end{array}$ & Legs, Thigh & Legs, face, arms \\
\hline \multirow{3}{*}{$\begin{array}{l}\text { Resolution } \\
\text { method }\end{array}$} & Cessation of fentanyl & Reduction of & Treatment with & \multirow{3}{*}{$\begin{array}{l}\text { NA (Continued } \\
\text { weight gain) }\end{array}$} \\
\hline & \multirow[b]{2}{*}{ Return to long-acting morphine } & $150 \mathrm{mg} /$ day & spironolactone & \\
\hline & & $\begin{array}{l}\text { Oxycodone SR } \\
360 \mathrm{mg} / \text { day }\end{array}$ & $\begin{array}{l}\text { Reduction of } \\
\text { oxycodone to } 100 \mathrm{mg} \\
\text { TDS }\end{array}$ & \\
\hline
\end{tabular}

A focused review of past reported cases (Table 1) illustrates that longstanding, heavy and ongoing opioid use is the usual setting in which edema emerges. However, circumstances of such heavy use can align well with any of the above hypotheses, as all of them can explain edema emerging beyond a dosage and duration watershed. Such occurrence of edema fails to implicate any one mechanism more strongly than the other, and analysis from this point of view seems to have yielded all the information it could have.

Studied patient's is the first reported case authors have seen in their centre where idiopathic edema emerged after cessation of heavy opioid use. From a purely empirical point of view, it was in retrospect propitious that we were unable to provide the patient with opioid substitution - it forced a change in point of view, otherwise our patient's symptoms would have almost certainly have been attributed to the substitution opioid. Reformed abusers who never received OST have remained a largely unstudied population - a PubMed search using "opioid-related disorders" and "edema" produced no studies about this clinical niche.

Without being dogmatic, a rigorous exclusion process of conceivable causes of the edema was performed. A subsequent a priori Naranjo algorithm assessment deemed it 'probable' that the opioids she had abused were responsible for the edema (Score 6, cut-off for probability being 5$){ }^{18}$

Certain clinical features provide grounds for novel speculations regarding the possible mechanism of opioid induced edema. Studied patient had a characteristic pattern of edema distribution (periorbital onset with progression to 
pedal edema), normal JVP and a resolution of edema only happened on addition of an aldosterone receptor antagonist (Spironolactone) to ongoing (ineffective) loop diuretic treatment. This narrative is consistent with Aldosterone's role in cardiovascular disease or triple-antihypertensive resistant hypertension.

It is recognized that primary hyperaldosteronism due to an adrenal adenoma or hyperplasia causes sodium retention, edema and hypertension. However, administration of large amounts of exogenous aldosterone to normal individuals does not cause edema. After some initial sodium-retaining effects of the administered aldosterone, urinary sodium excretion increases to balance intake before any edema forms (the so-called "aldosterone escape" mechanism). ${ }^{19} \mathrm{~A}$ breakdown of this mechanism takes place in the edematous cardiac failure patient, who despite an increase in both extracellular fluid and total plasma volume, continues to retain sodium in the kidneys. The cause seems to be a failure of the aldosterone escape mechanism. The normal escape mechanism involves increasing sodium delivery to the distal collecting duct, the site of mineralocorticoid action. The aldosterone escape does not occur in heart failure and cirrhosis because concurrent neurohumoral effects like reduced renal perfusion and increased alphaadrenergic activity decrease this distal sodium delivery. ${ }^{20}$

Relationships of distortion have been demonstrated between opioids and alpha-adrenergic activity, and between opioids and renal perfusion. ${ }^{21,22}$ This means the deleterious physiological effects of opioid abuse per se may proxy for the neurohumoral derangements of reduced cardiac output or primary peripheral arterial vasodilatation found in and engendering the pathology of the cardiac failure patient who does not 'aldosterone escape'. Furthermore, an aldosterone derangement in opioidinduced edema dovetails well with earlier, partiallysubstantiated hypotheses and findings implicating $\mathrm{ADH}$. Aldosterone may act on the central nervous system via the posterior pituitary gland to release vasopressin (ADH) thereby additionally conserving water by direct actions on renal tubular reabsorption. ${ }^{23}$ There is also evidence of an independent, nongenomic effect of aldosterone injuring endothelium. ${ }^{24}$ This too could contribute to both elevated $\mathrm{BP}$ and edema and be prevented by a mineralocorticoid antagonist.

The coherent narrative that forms by linking these varying earlier theories strengthens our hypothesis of failed aldosterone escape mediating opioid associated edema. It also suggests that aldosterone receptor antagonists will be a superior class of drugs in opioid associated edema. At the same time though, that pentazocine is a synthetic opioid agonist means that conclusively extending this reasoning to pure opioid agonists will require similar but separate work.

Secondly, that edema emerged long after cessation of opioid use means the dose and duration dependent use of opioids may not only precipitate edema, but potentially produce lasting changes in the (currently unclear) physiological pathway responsible. The major takeaway concerns the manner in which these changes appear stable and seem to persist well beyond the period of actual opioid use. If this be so, it merits a re-consideration of our understanding of the longitudinal trajectory of opioid abuse as a clinical entity - speaking purely physiologically, it is difficult to say when opioid users truly 'recover' as they may remain vulnerable to the drug effected derangements well after having stopped use.

Finally, studied patient's seemingly overlooked clinical 'niche' (reformed opioid abusers who never received OST) is actually a huge population - it is estimated that only $8 \%$ of injecting drug users globally currently receive OST 25 . This preliminary case highlights the need to conduct wellcontrolled, large sample studies on the huge numbers of recovered non-OST opioid abusers. Doing so will not only ascertain the workings of opioid induced edema, but considering the unique physiological status of these patients, likely yield valuable insights into the pathology of opioid use as a whole.

\section{CONCLUSION}

The patho-physiological changes in recovered non-OST opioid abusers could yield valuable information on the process of edema emerging in the context of opioid abuse. The collective symptom profile and medication response of our patient encouraged a hypothesis of failed aldosteroneescape as a possible cause. We would encourage largerscale and more systematic assessments of the phenomenon and hypothesis.

\section{Funding: No funding sources \\ Conflict of interest: None declared \\ Ethical approval: Not required}

\section{REFERENCES}

1. Gardner-Nix J. Opioids causing peripheral edema. Journal Pain Symptom Management. 2002 Jun $1 ; 23(6): 453-5$.

2. Mahé I, Chassany O, Grenard AS, Caulin C, Bergmann JF. Methadone and edema: a case-report and literature review. Eur J Clin Pharmacol. 2004 Feb 1;59(12):923-4.

3. Emeritus AD, Ruan X. Severe peripheral edema during an outpatient continuous epidural morphine infusion trial in a patient with failed back surgery syndrome. Pain Physician. 2008 May;11(3):363-7.

4. De Bodo RC. The antidiuretic action of morphine, and its mechanism. J Pharmacol Experimental Therapeutics. 1944 Sep 1;82(1):74-85.

5. Grell S, Christensen JD, Fjalland B. Morphine antidiuresis in conscious rats: contribution of vasopressin and blood pressure. Acta Pharmacol Toxicol. 1985 Jan;56(1):38-43.

6. Aziz LA, Forsling ML, Woolf CJ. The effect of intracerebroventricular injections of morphine on 
vasopressin release in the rat. J Physiol. 1981 Feb 1;311(1):401-9.

7. Firemark HM, Weitzman RE. Effects of $\beta$-endorphin, morphine and naloxone on arginine vasopressin secretion and the electroencephalogram. Neuroscience. 1979 Dec 1;4(12):1895-902.

8. Walker LA, Murphy JC. Antinatriuretic effect of acute morphine administration in conscious rats. J Pharmacol Experiment Therapeutics. 1984 May 1;229(2):404-8.

9. Danesh S, Walker LA. Effects of central administration of morphine on renal function in conscious rats. J Pharmacol Experiment Therapeutics. 1988 Feb 1;244(2):640-5.

10. Huidobro-Toro JP, Huidobro F. Central effects of morphine, levorphanol,(-)-methadone and the opioidlike peptides beta-endorphin and D-alanine2methionine enkephalinamide on urine volume outflow and electrolytes. J Pharmacol Experiment Therapeutics. 1981 Jun 1;217(3):579-85.

11. Rosow CE, Moss J, Philbin DM, Savarese JJ. Histamine release during morphine and fentanyl anesthesia. Anesthesiol. 1982 Feb;56(2):93-6.

12. Flacke JW, Flacke WE, Bloor BC, Van AE, Kripke BJ. Histamine release by four narcotics: a doubleblind study in humans. Anesthesia Analgesia. 1987 Aug;66(8):723-30.

13. Grossmann M, Abiose A, Tangphao O, Blaschke TF, Hoffman BB. Morphine-induced venodilation in humans. Clin Pharmacol Therapeutics. 1996 Nov;60(5):554-60.

14. Levy JH, Brister NW, Shearin A, Ziegler J, Hug JC, Adelson DM, et al. Wheal and flare responses to opioids in humans. Anesthesiol. 1989 May;70(5):75660 .

15. Hermens JM, Ebertz JM, Hanifin JM, Hirshman CA. Comparison of histamine release in human skin mast cells induced by morphine, fentanyl, and oxymorphone. Anesthesiol. 1985 Feb;62(2):124-9.

16. Barth H, Giertz H, Schmal A, Lorenz W. Anaphylactoid reactions and histamine release do not occur after application of the opioid tramadol. Agents Actions. 1987 Apr 1;20(3-4):310-3.

17. Aldrete JA, da Silva CJ. Leg edema from intrathecal opiate infusions. Eur J Pain. 2000 Dec;4(4):361-5.
18. Naranjo CA, Busto U, Sellers EM, Sandor P, Ruiz I, Roberts EA, et al. A method for estimating the probability of adverse drug reactions. Clin Pharmacol Therapeutics. 1981 Aug 1;30(2):239-45.

19. Schrier RW. Aldosterone 'escape' vs 'breakthrough'. Nat Rev Nephrol. 2010 Feb;6(2):61.

20. Schrier RW, Arroyo V, Bernardi M, Epstein M, Henriksen JH, Rodés J. Peripheral arterial vasodilation hypothesis: a proposal for the initiation of renal sodium and water retention in cirrhosis. Hepatol. 1988 Sep;8(5):1151-7.

21. Carr DJ, Gebhardt BM, Paul DE. Alpha adrenergic and mu-2 opioid receptors are involved in morphineinduced suppression of splenocyte natural killer activity. J Pharmacol Experiment Therapeutics. 1993 Mar 1;264(3):1179-86.

22. Arerangaiah R, Chalasani N, Udager AM, Weber ML, Manivel JC, Griffin RJ, et al. Opioids induce renal abnormalities in tumor-bearing mice. Nephron Experiment Nephrol. 2007;105(3):e80-9.

23. Pubchem. Aldosterone. Available at: https://pubchem.ncbi.nlm.nih.gov/compound/aldoster one\#section=Pharmacology-and-Biochemistry. Accessed on 13 October 2016.

24. Tsuchiya K, Yoshimoto T, Hirata Y. Endothelial dysfunction is related to aldosterone excess and raised blood pressure. Endocrine J. 2009;56(4):553-9.

25. Mathers BM, Degenhardt L, Ali H, Wiessing L, Hickman M, Mattick RP, et al. HIV prevention, treatment, and care services for people who inject drugs: a systematic review of global, regional, and national coverage. Lancet. 2010 Mar 20;375(9719):1014-28.

26. Longwell B, Betz T, Horton H, Witte CL, Witte MH. Weight gain and edema on methadone maintenance therapy. Int J Addictions. 1979 Jan 1;14(3):329-35.

Cite this article as: Ratnam A, Sashindran VK, Kanwar A. A case of idiopathic edema after opioid abuse cessation: can failed aldosterone escape be implicated?. Int J Basic Clin Pharmacol 2019;8:34650 . 